\title{
Effects of exendin-4, a glucagon like peptide-I receptor agonist, on neutrophil count and inflammatory cytokines in a rat model of endotoxemia
}

Ofer Yanay ${ }^{1,2}$

Adam L Bailey ${ }^{3}$

Kelly Kernan'

Jerry J Zimmerman ${ }^{1,2}$

William R Osborne'

'Department of Pediatrics, University of Washington, ${ }^{2}$ Division of Pediatric

Critical Care Medicine, Seattle Children's Hospital, Seattle, WA, ${ }^{3}$ Medical Scientist Training Program, University of Wisconsin, Madison, WI, USA

\author{
This article was published in the following Dove Press journal: \\ Journal of Inflammation Research \\ 24 July 2015 \\ Number of times this article has been viewed
}

Background: Sepsis remains a major cause of morbidity and mortality. A variety of strategies targeting modulation of the pro-inflammatory response associated with early sepsis have been reported without clinical success. GLP-1 enhances glucose-stimulated insulin secretion. In addition, it was shown to have anti-inflammatory effects. We hypothesized that treatment with exendin-4, a GLP-1 receptor agonist, would attenuate inflammation and improve glucose control in a lipopolysaccharide (LPS) rat model of inflammation.

Methods: Two-month-old male Wistar rats were randomly assigned to one of the following four groups: 1) treatment: intraperitoneal (IP) injection of LPS $10 \mathrm{mg} / \mathrm{kg}$ followed by exendin-4, $30 \mu \mathrm{g} / \mathrm{kg}, 10$ minutes later; 2) control-1: IP injection of LPS $10 \mathrm{mg} / \mathrm{kg}$, followed by normal saline (NS); 3) control-2: IP NS injection followed by exendin-4; 4) sham: IP injection of NS followed by another NS injection. Glucose concentration, total white blood count with absolute neutrophil count, and pro- and anti-inflammatory cytokine concentrations were measured at 0 , 3, 6, and 10 hours following LPS injection.

Results: At 3 hours, rats injected with LPS developed neutropenia, elevated pro- and antiinflammatory cytokines, and mild hypoglycemia. Treatment with exendin-4 significantly modulated neutropenia, and decreased pro-inflammatory cytokine concentrations (IL-1 $\alpha$, IL-1 $\beta$, IL-6, TNF $\alpha$, and IFN $\gamma$ ). However, exendin-4 had no effect on IL-10 concentrations. LPS injection led to mild hypoglycemia, that was not observed in rats treated with exendin-4. Sham animals exhibited no significant change from baseline in all parameters.

Conclusion: In this LPS model of acute early phase inflammation, treatment with exendin-4 decreased pro-inflammatory cytokine concentrations without changing IL-10 blood levels and improved neutropenia. Following LPS injection, rats developed a tendency toward hypoglycemia that improved with exendin-4. Overall our data suggest that exogenous exendin-4 mediates antiinflammatory effects early in this rat model of endotoxin-induced inflammation.

Keywords: glucagon like peptide-1, exendin-4, sepsis, endotoxemia, inflammation, neutrophils

\section{Background}

Sepsis remains a significant health problem and a major cause of morbidity and mortality. ${ }^{1,2}$ Although both pro-inflammatory and anti-inflammatory responses begin rapidly with sepsis, the initial response in patients with severe sepsis is typified by an overwhelming hyper-inflammatory phase mediated by a variety of pro-inflammatory cytokines. ${ }^{3,4}$

Over the last 15 years an increasingly robust body of literature has described the deleterious effects of hyperglycemia in a variety of clinical contexts including sepsis.
Department of Pediatrics, University of Washington, Seattle Children's Hospital FA.2.I 12, 4800 Sand Point Way NE, Seattle, WA 98105 , USA

$\mathrm{Tel}+|206987539|$

Fax +l 2069873866

Email ofer.yanay@seattlechildrens.org 
Glycemic control using insulin infusion has provided conflicting results with earlier studies showing benefits with decreased mortality in subgroups of adult patients, but subsequent studies showing no benefit and potential harm associated with complications, most importantly hypoglycemia. ${ }^{5-7}$

GLP-1 is a tissue-specific post-translational proteolytic product of the proglucagon gene, released from intestinal L-cells in response to nutrient ingestion that enhances glucose-stimulated insulin secretion. ${ }^{8}$ GLP-1 is one of the major incretin hormones in humans and has been studied extensively in association with type 2 diabetes. ${ }^{9,10}$

The biologic effects of GLP-1 and GLP-1 receptor agonists (GLP-1RA) in association with glucose control are well studied and include: 1) stimulation of glucose-dependent insulin secretion; 2) inhibition of glucagon and stimulation of somatostatin secretion; 3 ) stimulation of $\beta$-cell proliferation and neogenesis and inhibition of $\beta$-cell apoptosis, thereby increasing $\beta$-cell mass; 4 ) activation of the expression of immediate early genes encoding transcription factors that regulate islet cell proliferation and differentiation. ${ }^{11}$ GLP-1 was shown to be an effective treatment for type 2 diabetic patients, and its analogs are currently in clinical use in this group of patients. ${ }^{10,12}$

The GLP-1 receptor (GLP-1R) is well characterized, cloned, and sequenced. It is expressed in a wide range of organs including $\alpha-, \beta$-, and $\delta$-cells of the pancreatic islets, lung, heart, kidney, stomach, intestine, pituitary, skin, nodose ganglion neurons of the vagus nerve, and several regions of the central nervous system including the hypothalamus and brainstem. ${ }^{13,14}$ With this wide organ distribution it is likely that GLP-1 plays a role in organs apart from the pancreas.

Anti-inflammatory properties of GLP-1 have been studied in vitro, with promising results in cells derived from a variety of organs (lung, myocardium, neurons). ${ }^{15-17}$

In vivo animal studies showed a wide range of antiinflammatory effects of GLP-1RA in the cardiovascular system, endothelium, intestine, kidneys, and the brain. ${ }^{18-23}$

More recently, a study among humans with obesity and type 2 diabetes mellitus reported decreased levels of proinflammatory cytokines in patients treated with exenatide (another GLP-1RA). ${ }^{24}$

Exendin-4 (Ex-4) is a specific GLP-1RA purified from Heloderma suspectum venom. ${ }^{25,26}$

The current study was designed to evaluate the effects of Ex-4, on inflammation and glycemic control in a rat model of endotoxin (lipopolysaccharide [LPS])-induced inflammation. We hypothesized that treatment with Ex-4, would reduce inflammation and improve glycemic control without adverse effect of hypoglycemia.

\section{Materials and methods Animals}

Two-month-old male Wistar rats (Harlan Laboratories, Indianapolis, IN, USA) weighing 200-250 g, were used in all experiments. Rats were housed under specific pathogen free conditions using a standard 12:12 hour light/dark cycle and received regular diet and water ad libitum. Experiments were conducted at least 5 days following transfer to allow acclimatization.

\section{Inflammation protocol}

Rats were divided into four groups: the treatment group received a $10 \mathrm{mg} / \mathrm{kg}$ intraperitoneal (IP) injection of Escherichia coli LPS (from E. coli, EH100, Sigma-Aldrich Co, St Louis, MO, USA), followed by a $30 \mu \mathrm{g} / \mathrm{kg}$ IP injection of Ex-4 (Sigma-Aldrich Co) 10 minutes later (LPS/Ex-4 group, $\mathrm{n}=11$ ). One control group, received the IP LPS injection followed by a normal saline (NS) injection 10 minutes later (LPS/NS, n=6). To rule out any effects associated with the Ex-4, another control group received an IP NS injection followed by a $30 \mu \mathrm{g} / \mathrm{kg}$ injection of Ex-4 (NS/Ex-4, n=6). A sham group received an IP NS injection followed by another NS injection 10 minutes later (NS/NS, n=4). Blood samples for all tests were collected from the lateral vein tail at $0,3,6$, and 10 hours following initial injection. Ten hours after LPS or NS injection, rats were euthanized using pentobarbital overdose IP injection. All animal studies were approved by the Institutional Animal Care and Use Committee at the University of Washington.

\section{Biochemical analyses}

\section{Plasma glucose}

Plasma glucose concentrations were measured with a glucometer (Ascensia Contour, Bayer AG, Leverkusen, Germany).

\section{Complete blood count}

Complete blood count was obtained using a Coulter counter (Hemavet 950FS; Drew Scientific Inc., Oxford, CT, USA). Leukocyte differential was confirmed with blood smears and manual counting.

\section{GLP-I assays}

Blood samples for GLP-1 were collected in a tube with ethylenediaminetetraacetic acid (EDTA) and dipeptidyl peptidase IV inhibitor (EMD Millipore, Billerica, MA, USA). 
Samples were cooled on ice, fractionated by centrifugation at $10,000 \times \mathrm{g}$ for 5 minutes, and the plasma stored at $-20^{\circ} \mathrm{C}$. GLP-1 concentrations were measured using total active GLP-1 assay kit (Meso Scale Discovery, Gaithersburg, MD, USA).

\section{Cytokine assays}

Blood for cytokine analyses was maintained at room temperature for 10 minutes to allow clotting. Subsequently it was fractionated by centrifugation at $10,000 \times g$ for 5 minutes. Resultant serum was stored until analysis at $-20^{\circ} \mathrm{C}$. Cytokines' concentrations were measured using the multiplex beads - Discovery assay (Eve Technologies Corporation, Calgary, CA, USA).

\section{Ex-4}

Serum Ex-4 concentrations were measured using an enzymelinked immunosorbent assay (ELISA) kit (Phoenix Pharmaceuticals, Burlingame, CA, USA).

\section{Statistics}

All numerical data are presented as group means with standard error of the mean (SEM). $P$-values for glucose levels and absolute neutrophil count (ANC) were determined using Student's two-tailed $t$-test at the stated time points. To derive $P$-values for cytokine levels we used a Student's $t$-test and two-way analysis of variance using Bonferroni's multiple comparison test. Statistical analysis was performed using a program supplied by GraphPad Software Inc., La Jolla, CA, USA.

\section{Results}

\section{Clinical changes}

Rats in the LPS/NS group developed behavior changes including lack of grooming, reduced mobility, eating bedding, and attempted to hide. Treatment group (LPS/Ex-4) exhibited minimal changes (mostly lack of grooming and reduced mobility). Control groups had no behavioral changes.

\section{Glucose concentrations}

Surprisingly rats in the LPS/NS group, showed no signs of hyperglycemia, a common feature of human sepsis associated with stress mediated gluconeogenesis. In fact, the LPS/NS group, exhibited a tendency toward hypoglycemia. Treatment with Ex-4 (LPS/Ex-4 group) provided no statistically significant impact on glucose concentrations. However, there was a trend toward normoglycemia (glucose concentration of $70-130 \mathrm{mg} / \mathrm{dL}$ ) in the treatment group especially at 3 and 6 hours. Interestingly, rats treated with Ex-4 only (NS/Ex-4), exhibited a tendency toward mild hyperglycemia. Sham group (NS/NS) showed no significant change in glucose concentrations from baseline (Figure 1A).

\section{Neutrophil counts}

Mean ANC was 3.8 (range 2.38-4.97) $\times 10^{3}$ cells $/ \mu \mathrm{L}$ at baseline with no significant differences between groups. Sham (NS/NS) rats and rats treated with Ex-4 only (NS/Ex-4) exhibited no significant changes from baseline throughout the experiment. Rats injected with LPS/NS developed significant neutropenia with minimal recovery at 10 hours, when compared to sham rats (NS/ NS) $(P<0.001$ at 3 and 6 hours, $P<0.01$ at 10 hours $)$. Treatment with Ex-4 (LPS/Ex-4 group) significantly improved neutrophil
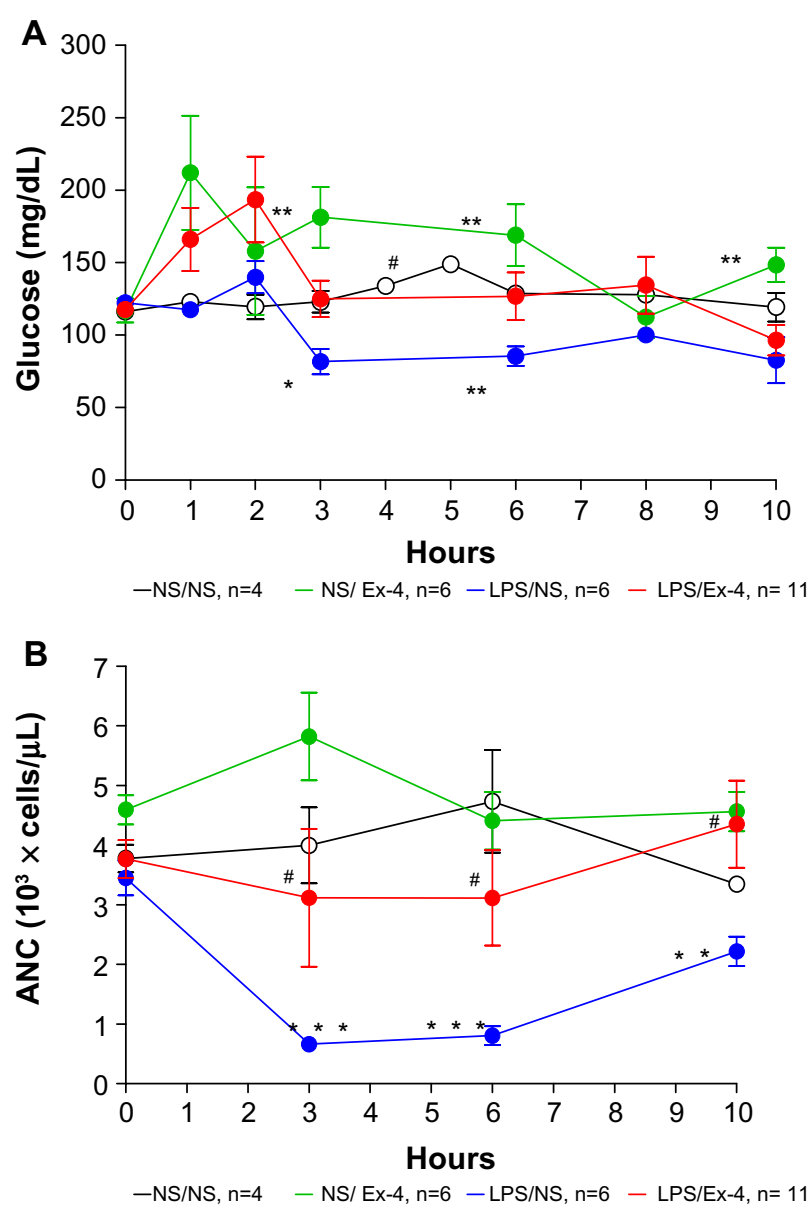

Figure I Longitudinal changes in glucose levels and ANC's.

Notes: (A) Longitudinal changes in serum glucose concentrations in the rat LPS model of sepsis. (B) Longitudinal changes in absolute neutrophil count (ANC) in the rat LPS model of sepsis. Values are group means \pm SD. Comparison done at each given time point $(0,3,6$, and 10 hours). " refers to LPS/NS (blue line) versus LPS/Ex-4 (red line); * refers to LPS/NS (blue line) versus NS/NS (black line); ${ }^{*}$ and *: $P<0.05$; **: $P<0.01$, ***: $P<0.001$.

Abbreviations: LPS, lipopolysaccharide; NS, normal saline; Ex-4, Exendin-4; SD, standard deviation. 
counts at 3, 6, and 10 hours post-injection ( $P<0.05$ at 3 hours). $\mathrm{ANC}$ in the treatment group (LPS/Ex-4) was not statistically different from the sham rats (NS/NS) (Figure 1B).

\section{Inflammatory cytokines}

\section{IL-I $\alpha$}

IL-1 $\alpha$ was elevated at 6 hours following LPS injection in the control group (LPS/NS) compared to sham rats. Treatment with Ex-4 decreased IL-1 $\alpha$ significantly $(P<0.05)$.

\section{IL-I $\beta$}

IL-1 $\beta$ was elevated at 3, 6, and 10 hours following LPS injection compared to the sham group. Treatment with Ex-4 reduced IL-1 $\beta$ concentrations. However, it reached statistical significance only at 6 hours $(P<0.05)$ mostly due to wide standard deviation in the LPS group.

\section{IL-6}

LPS injection led to elevated IL-6 blood levels at 3 hours with a trend back toward baseline at 10 hours. Levels were significantly greater than the sham group at 3 hours $(P<0.001)$ and at 6 and 10 hours $(P<0.01)$. Treatment with Ex-4 decreased IL-6 levels at 3 and 10 hours $(P<0.05)$, and at 6 hours $(P<0.01)$.

\section{TNF $\alpha$}

TNF $\alpha$ levels peaked at 3 hours post-LPS injection with return to baseline at 10 hours. Treatment with Ex-4 decreased TNF $\alpha$ levels at 3 hours $(P<0.001)$, and at 6 hours $(P<0.05)$. Sham and NS/Ex-4 groups demonstrated no change in TNF $\alpha$ levels throughout the experiment.

\section{IFN $\gamma$}

IFN $\gamma$ levels peaked at 6 hours post-LPS injection. Treatment with Ex-4 decreased IFN $\gamma$ levels significantly $(P<0.05)$. IFN $\gamma$ remained undetectable in the sham $(\mathrm{NS} / \mathrm{NS})$ and $\mathrm{Ex}-4$ only (NS/Ex-4) groups.

\section{IL- I0}

In contrast to a variety of pro-inflammatory cytokines, IL-10 levels were significantly increased at 3, 6, and 10 hours, in both control and treatment groups compared to sham and NS/Ex-4 groups $(P<0.01-0.05)$. However, there was no difference between control and treatment groups (Figure 2).

\section{GLP-I concentrations}

Plasma GLP-1 levels ranged from 15 to $68 \mathrm{pg} / \mathrm{mL}$ with no significant change in levels between groups and time course.
Of note, rats had free access to food, but experiments took place during light hours, a time they typically fast.

\section{Ex-4 concentrations}

Ex-4 levels were non-detectable at time 0 in all groups. Levels remained undetectable at all time points in the sham and LPS/NS groups. Rats treated with Ex-4 (LPS/Ex-4 or $\mathrm{NS} / \mathrm{Ex}-4$ ) had mean levels of $2-5 \mathrm{ng} / \mathrm{mL}$ at 3 hours returning to 0 at 6 and 10 hours (data not shown).

\section{Discussion}

In this study, we report that treatment with Ex-4 decreases pro-inflammatory cytokine levels, with no effects on IL-10 levels in the early phase of LPS-induced endotoxemia. We also show attenuation of neutropenia which was prominent in this rat model of early sepsis. To our best knowledge, this is the first study examining the effect of a GLP-1RA in a rat model of LPS-induced inflammation. Elevated proinflammatory markers, especially in early sepsis, indicate excessive inflammatory host response and are correlated with severe sepsis and worse outcome. ${ }^{27,28}$

Systemic inflammatory response syndrome is defined as systemic inflammatory response to a variety of severe clinical insults. The response is manifested by two or more of the following conditions: hypo/hyperthermia, tachycardia, tachypnea, and leukocytosis or neutropenia. ${ }^{29}$ IL-1 and TNF $\alpha$-are strong pro-inflammatory cytokines, released shortly after the inciting event, and are early regulators of the immune response. They are also strong pyrogenic cytokines. ${ }^{4}$ IL-6 is produced in response to stimulation with LPS, IL-1, and TNFo. It has a variety of biological effects including activation of $\mathrm{T}$ and $\mathrm{B}$ lymphocytes and the coagulation system. It is also a strong pyrogenic cytokine. ${ }^{4}$ In our study, Ex-4 attenuated levels of these pro-inflammatory cytokines at the very early phase of inflammation. There is likely a role for drugs that block inflammatory cytokines in sepsis; however, such agents should be short acting, applied early in sepsis, and used only in patients who have substantially elevated pro-inflammatory cytokines. ${ }^{3}$

Leukocytosis is the usual response to bacterial infection. Neutropenia in septic animals and humans, may be secondary to enhanced leukosequestration at the site of infection (site of LPS injection in our model) or within the lungs, as an antecedent to sepsis-associated acute lung injury, and is associated with worse outcome. In our rat model, treatment with Ex-4 improved ANC throughout the experiment period, indicating an additional favorable effect of GLP-1RA in this rat model. 

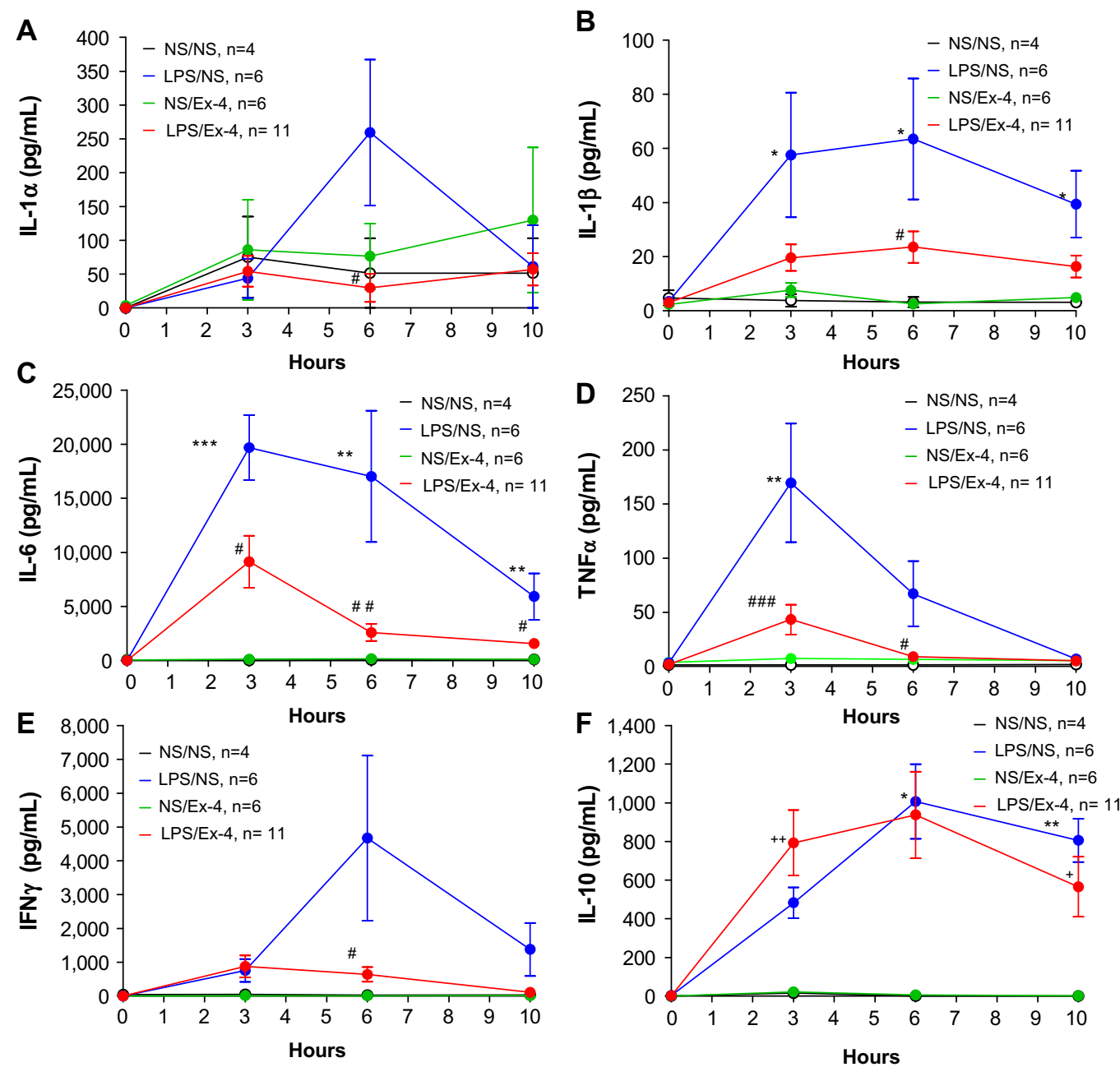

Figure 2 Longitudinal changes in serum inflammatory cytokine concentrations in the rat LPS model of sepsis.

Notes: Values are group means \pm SD. Comparison done at each given time point $\left(0,3,6\right.$, and 10 hours). ${ }^{*}$ refers to comparison of LPS/NS versus LPS/Ex-4; $*$ refers to

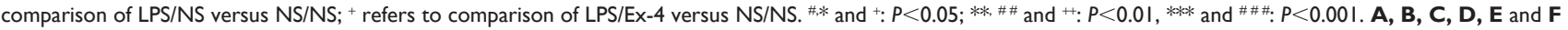
are presenting longitudinal changes in different serum inflammatory concentrations as determined by each $y$-axis title.

Abbreviations: LPS, lipopolysaccharide; NS, normal saline; Ex-4, Exendin-4; SD, standard deviation.

GLP-1RA have been approved by the US Food and Drug Administration(FDA) for treatment for type 2 diabetic patients. A recent study demonstrated the anti-inflammatory effects of GLP-1RA in obese humans with type 2 diabetes. ${ }^{24}$ The benefits of better glycemic control without the risk of hypoglycemia and the potential to reduce inflammation led us to assess the effects of treatment with Ex-4, a GLP-1RA, in this in vivo rat model of LPS-induced inflammation. One of our goals was to evaluate the effects of Ex-4 on hyperglycemia, a common manifestation of the stress response in critically ill patients. Glycemic control can be achieved with insulin infusion, but this intervention has the real risk of hypoglycemia. GLP-1RA has been shown to reduce insulin needs and decrease glucose levels in diabetic patients following major surgery. ${ }^{30}$ In this study, all rats administered with LPS, developed hypoglycemia or remained in the lower range of normoglycemia. Although no statistically significant differences were found between the groups, rats treated with Ex-4 exhibited a tendency toward higher (more normal) glucose levels. Hypoglycemia was reported in rat models of endotoxemia, thought to be associated with reduced gluconeogenesis, and linked to decreased mitochondrial phosphoenolpyruvate carboxykinase. ${ }^{31}$ Lower levels of IL-1 and TNF $\alpha$ associated with treatment with Ex-4, may have helped to prevent hypoglycemia seen in untreated rats in our study but further investigation is needed to better understand the underlying mechanism. Rats treated with NS/ Ex-4 demonstrated an increase in glucose levels at 1 hour with marginally high glucose levels at 3 and 6 hours. This phenomenon was described before..$^{32}$ It is reasonable to suggest that these effects of Ex-4 are not dependent on its interaction with GLP-1R only. 
GLP-1RA might offer the potential for safe glucose control without risks for hypoglycemia among critically ill patients, including those with sepsis, however, this rat model of endotoxemia failed to demonstrate this phenomenon frequently seen in humans. There are currently two FDA-approved GLP-1RA analogs, liraglutide and exenatide (synthetic Ex-4), being used for type 2 diabetes. Additionally, there are many other GLP-1RA in advanced stages of development (albiglutide, taspoglutide, lixisenatide, CJC-1134) likely to be approved in the near future.

These drugs are potential candidates for glycemic control in septic human patients with low risk for hypoglycemia.

We recognize several limitations in this experimental study. This LPS model is a sterile form of systemic inflammatory response syndrome rather than full clinical model of sepsis. Results should be interpreted accordingly and further studies using cecal ligation and puncture or other clinical models of sepsis are needed. Our study was limited to 10 hours follow-up and focused on the initial phase of sepsis. We did not explore potential mechanisms for Ex-4 effects. We did not compare different doses of Ex-4. In contrast to humans, rats did not demonstrate significant hyperglycemia in this model. Hence our ability to assess the effects of Ex-4 on glucose homeostasis in this sepsis model is limited.

\section{Conclusion}

Taken together, the results of our study, indicate that Ex-4 a GLP-1RA reduces inflammation and improves neutropenia during early phase of endotoxemia. Additional animal in vivo studies using a bacterial model of sepsis are needed to establish effects of this treatment on mortality. Further experiments are needed to define mechanisms by which Ex-4 is operating to modulate the inflammatory response. A different animal model, or direct human application will be needed to assess effects of GLP-1RA on glycemic control in sepsis.

\section{Acknowledgments}

This study was supported by Academic Enrichment Fund, Seattle Children's Hospital (OY); U10 HD049945, Eunice Kennedy Shriver NIH/NICHD Collaborative Pediatric Critical Care Research Network (JJZ). Virus Molecular Biology and Cell Core of the University of Washington Diabetes and Endocrinology Research Center NIH P30 DK017047 (WRO).

\section{Disclosure}

The authors have no conflicts of interest to disclose in this work.

\section{References}

1. Martin GS, Mannino DM, Eaton S, Moss M. The epidemiology of sepsis in the United States from 1979 through 2000. N Engl J Med. 2003;348(16):1546-1554.

2. Angus DC, Linde-Zwirble WT, Lidicker J, Clermont G, Carcillo J, Pinsky MR. Epidemiology of severe sepsis in the United States: analysis of incidence, outcome, and associated costs of care. Crit Care Med. 2001;29(7):1303-1310.

3. Hotchkiss RS, Monneret G, Payen D. Immunosuppression in sepsis: a novel understanding of the disorder and a new therapeutic approach. Lancet Infect Dis. 2013;13(3):260-268.

4. Schulte W, Bernhagen J, Bucala R. Cytokines in sepsis: potent immunoregulators and potential therapeutic targets - an updated view. Mediators Inflamm. 2013;2013:165974.

5. Van den Berghe G, Wouters P, Weekers F, et al. Intensive insulin therapy in critically ill patients. $N$ Engl J Med. 2001;345(19):1359-1367.

6. Vlasselaers D, Milants I, Desmet L, et al. Intensive insulin therapy for patients in paediatric intensive care: a prospective, randomized control study. Lancet. 2009;373(9663):547-556.

7. The NICE SUGAR Study investigators, Finfer S, Chittock DR, et al. Intensive versus conventional glucose control in critically ill patients. N Engl J Med. 2009;360(13):1283-1297.

8. Baggio LL, Drucker DJ. Biology of Incretins: GLP-1 and GIP. Gastroenterology. 2007;132(6):2131-2157.

9. Zander M, Madsbad S, Madsen JL, Holst JJ. Effect of 6-week course of glucagon-like peptide-1 on glycaemic control, insulin sensitivity, and beta-cell function in type 2 diabetes: a parallel-group study. Lancet. 2002;359(9309):824-830

10. Shyangdan DS, Royle P, Clar C, Sharma P, Waugh N, Snaith A. Glucagon-like peptide analogues for type 2 diabetes mellitus. Cochrane Database Syst Rev. 2011;(10):CD006423.

11. Kim W, Egan JM. The role of incretins in glucose homeostasis and diabetes treatment. Pharmacol Rev. 2008;60(4):470-512.

12. Lind M, Jendle J, Torffvit O, Lager I. Glucagon-like peptide 1 (GLP-1) analogue combined with insulin reduces $\mathrm{HbAlc}$ and weight with low risk of hypoglycemia and high treatment satisfaction. Prim Care Diabetes. 2012;6(1):41-46.

13. Bullock BP, Heller RS, Habener JF. Tissue distribution of messenger ribonucleic acid encoding the rat glucagon-like peptide-1 receptor. Endocrinology. 1996;137(7):2968-2978.

14. Dunphy JL, Taylor RG, Fuller PJ. Tissue distribution of rat glucagon receptor and GLP-1 receptor gene expression. Mol Cell Endocrinol. 1998;141(1-2):179-186.

15. Benito E, Blazquez E, Bosch MA. Glucagon-like peptide-1-(7-36)amide increases pulmonary surfactant secretion through a cyclic adenosine $3^{\prime} 5^{\prime}$-monophosphate-dependent protein kinase mechanism in rat type II pneumocytes. Endocrinology. 1998;139(5): 2363-2368.

16. Huisamen B, Genade S, Lochner A. Signaling pathways activated by glucagon-like peptide-1 (7-36) amide in the rat heart and their role in protection against ischemia. Cardiovasc J Afr. 2008;19(2): $77-83$.

17. Iwai T, Ito S, Tanimitsu K, Udagawa S, Oka J. Glucagon-like peptide-1 inhibits LPS induced IL-1beta production in cultured rat astrocytes. Neurosci Res. 2006;55(4):352-360.

18. Sonne DP, Engstrom T, Treiman M. Protective effects of GLP-1 analogues exendin-4 and GLP-1(9-36) amide against ischemia reperfusion injury in rat heart. Regul Pept. 2008;146(1-3):243-249.

19. Dokken BB, La Bonte LR, Davis-Gorman G, Teachey MK, Seaver N, McDonagh PF. Glucagon-like peptide-1 (GLP-1) immediately prior to reperfusion, decreases neutrophil activation and reduces myocardial Infarct size in rodents. Horm Metab Res. 2011;43(5):300-305.

20. Ku SK, Han MS, Park EJ, Na DH, Bae JS. Exendin-4 inhibits endothelial protein $\mathrm{C}$ receptor shedding in vitro and in vivo. Pharmacol Res. 2014; 84:18-25.

21. Kissow H, Hartmann B, Holst JJ, Poulsen SS. Glucagon-like peptide-1 as a treatment for chemotherapy-induced mucositis. Gut. 2013; 62(12): $1724-1733$. 
22. Kodera R, Shikata K, Kataoka HU, et al. Glucagon-like peptide-1 receptor agonist ameliorates renal injury through its anti-inflammatory action without lowering blood glucose level in a rat model of type 1 diabetes. Diabetologia. 2011;54(4):965-978.

23. Iwai T, Sawabe T, Tanimitsu K, Suzuki M, Sasaki-Hamada S, Oka J. Glucagon-like peptide-1 protects synaptic and learning functions from neuroinflammation in rodents. $J$ Neurosci Res. 2014;92(4):446-454.

24. Chaudhuri A, Ghanim H, Vora M, et al. Exenatide exerts a potent antiinflammatory effect. J Clin Endocrinol Metab. 2012;97(1):198-207.

25. Eng J, Kleinman WA, Singh L, Singh G, Raufman JP. Isolation and characterization of exendin-4, an exendin-3 analogue, from Heloderma suspectum venom. J Biol Chem. 1992;267(11):7402-7405.

26. Goke R, Fehmann HC, Linn T, et al. Exendin-4 is a high potency agonist, and truncated Exendin-(9-39)-amide an antagonist at the glucagon like peptide 1-(7-36)-amide receptor of insulin secreting $\beta$ cells. $J$ Biol Chem. 1993;268(26):19650-19655.

27. Badiu DC, Paunescu V, Aungurenci A, Pasarica D. Proinflammatory cytokines in peritonitis. J Med Life. 2011;4(2):158-162.
28. Kellum JA, Kong L, Fink MP, et al. Understanding the inflammatory cytokine response in pneumonia and sepsis: results of the Genetic and Inflammatory Markers of Sepsis (GenIMS) Study. Arch Intern Med. 2007;167(15):1655-1663.

29. No authors listed. American College of Chest Physicians/Society of Critical Care Medicine Consensus Conference: definitions for sepsis and organ failure and guidelines for the use of innovative therapies in sepsis. Crit Care Med. 1992;20(6):864-874.

30. Meier JJ, Weyhe D, Michaely M, et al. Intravenous glucagon-like peptide 1 normalizes blood glucose after major surgery in patients with type 2 diabetes. Crit Care Med. 2004;32(3):848-851.

31. Caton PW, Navuni NK, Murch O, Corder R. Endotoxin induced hyperlactatemia and hypoglycemia is linked to decreased mitochondrial phosphoenolpyruvate carboxykinase. Life Sci. 2009;84(21-22):738-744.

32. Malendowicz LK, Nowak KW. Preproglucagon derived peptides and thyrotropin (TSH) secretion in the rat: robust and sustained lowering of blood TSH levels in exendin-4 injected animals. Int $J$ Mol Med. 2002;10(3):327-331.
Journal of Inflammation Research

\section{Publish your work in this journal}

The Journal of Inflammation Research is an international, peer-reviewed open-access journal that welcomes laboratory and clinical findings on the molecular basis, cell biology and pharmacology of inflammation including original research, reviews, symposium reports, hypothesis formation and commentaries on: acute/chronic inflammation; mediators of inflamma-

\section{Dovepress}

tion; cellular processes; molecular mechanisms; pharmacology and novel anti-inflammatory drugs; clinical conditions involving inflammation. The manuscript management system is completely online and includes a very quick and fair peer-review system. Visit http://www.dovepress.com/ testimonials.php to read real quotes from published authors.

Submit your manuscript here: http://www.dovepress.com/journal-of-inflammation-research-journal 